\title{
LESSER KNOWN MUSICAL INSTRUMENTS IN KOSOVO
}

\section{Rešad Fazli ${ }^{1}$}

Professional paper

Received: 29.01.2012

UDC: 787/789(497.115)

Accepted: 15.04 .2012

\begin{abstract}
In this paper the author presented the instruments that were originated in this region, as well as those instruments that are brought from other regions, and became deeply carved into the tradition and culture of the local people, that they feel as their own. Some of these instruments are kept only here in this region, and they are not used anymore in the area they originated from. This paper also covers instruments that are rarely used or completely lost in this region.
\end{abstract}

Keywords: string instruments, brass instruments, membranophones, percussion, male and female instruments.

\section{METHODS}

classifications, descriptions, interview

\section{DISCUSSION}

This paper is the result of field research and the fact-finding from: Sefer Skenderi, Pousko, Medžit Skenderi, Jablanica. Instruments are divided for certain kinds of festivities they are used for, for the larger and smaller celebrations, instruments used in solo performances, and those used as the accompanying instruments. Instruments that must go in pairs (Çift) are also mentioned. More than four instruments are rarely used in the band.

The people in our region in the past, although the present is not much prone to them either, were overwhelmed with many forms of severe adversities, material and existential harsh conditions, so they weren't able to sufficiently improve and develop their musical culture, as did the other nations in the region, who enjoy their freedom and privileges. Most of the high quality and expensive instruments, never reached our region. Therefore, vocal music forms were more developed than instrumental music. The most used musical instruments from our country in the past, are:

\section{SVIRALE/FIFE(flute/frule or šupeljke):}

Distribution maps of particular instruments indicate that in all cultural areas, however, the most important and most pervasive were different pastoral flutes that accompanied the songs and dances. We can distinguish fifty names and forms: Flute/frula (taken from the Romanian word "fleur"),

1 Correspodence to:

Rešad Fazli

Prizren, Kosovo

E-mail: resat_fazli@hotmail.com 
sviraljka, šupeljka, sviraljče, sviravka, cevara, covara, duduk, duduče, trill, ćurlikalica... They were made by the shepherds, mainly from straight, lateral tree branches of a certain diameter, never from a trunk or stump. That they love their flutes, that they were important to them, is evident from patterns of different motifs, carved or burnt in by hot wire, which were always happy and playful. Sheep and lambs were first and foremost audience of the music shepherds play. When mothers was seeing off shepherds in the dawn with their sheep, they always reminded them not to forget their fife/ šupeljka. They usually played the flute when the herd is quietly grazing or resting on pasture.

\section{How to make a fife/svirala?}

It is necessary to obtain a single branch chopped in the fall so it can be well dried during the winter, and a sharp knife to remove bark. Then, to make adhesive you'll need one egg white, three to four crushed garlic cloves, and an egg sized piece of resin from the plum tree. When you gather all this material, you can start making the fife in this manner: first remove bark from branch, and than put a knife in the center of branch and with a strong hammer stroke split it in two equal halves. Pour milk over branch halves in order to better fit to one another, and bind them tightly together with twisted wool so that it doesn't buckle. Allow them to dry until spring. After that, carefully paste halves along the slit with mixture of egg-white, garlic and resins.

Repeatedly coat the pipe with oil and vinegar, to prevent wood absorbing saliva when played. By putting pipes into the roast, mostly in mutton, fife soaks in the grease and in that way gets impregnated. Such kinds of fifes are not made for sale. Those with weaker sound are given to children, and the best one is kept to yourself. Fifes/svirale are considered as legacy, and usually inherited from father to son."
ŠUPELJKA - an instrument similar to the kaval, only smaller in size, usually made of plum tree or boxwood, but also from buffalo horn. The name of this instrument derives from completely hollowedout pipe, hollow and open at both ends. As a shepherd's instrument, it's represented in almost all Balkan nations.

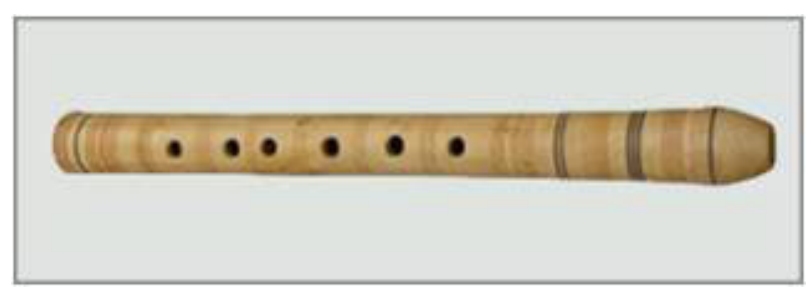

Figure 1 .

DVOJNICE - shepherds solo instrument used to perform melancholy tunes, so it could be heard in the past at the rural routs, parties and other kinds of social events. Most often made of plum, wild pear, acacia, cherry or birch wood. Dvojnice are double barreled flute, made of two individual pipes of the same length from one piece of wood. The finger holes used to play it are positioned on the face side, and one tube has four, and the other one three holes. When played, player blows in both tubes at the same time, so it's possible for one player to perform two-voice melodies.

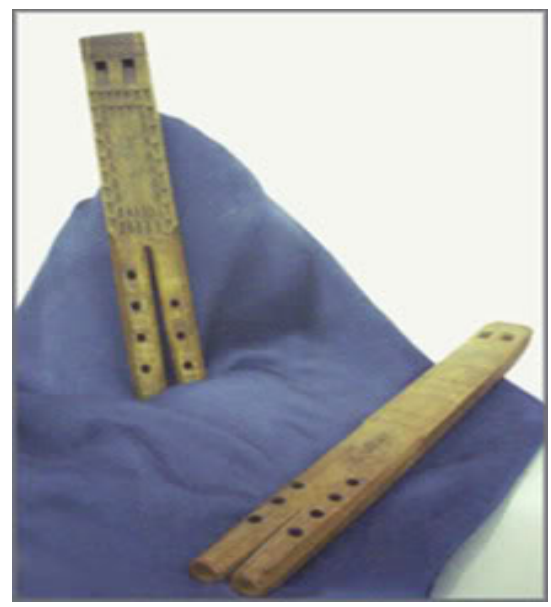

Figure 2. 
GAJDE or MEŠNICE (bagpipes) - the name derives from the Arabic word "Gaida" - melody. Under that name, or a slightly altered version, we can came across this instrument all over the South Slavic region, as well as Hungarian, Bulgarian, Slovak, Spanish, Portuguese, etc. Bagpipes are aerophone, solo instrument, composed of the skins and the wooden parts. It is very hard to coordinate the two bagpipes, so they are rarely played together. Even If they're joined, it's used only to perform a melody in unison. Their use was not widespread and it didn't retain to this day.

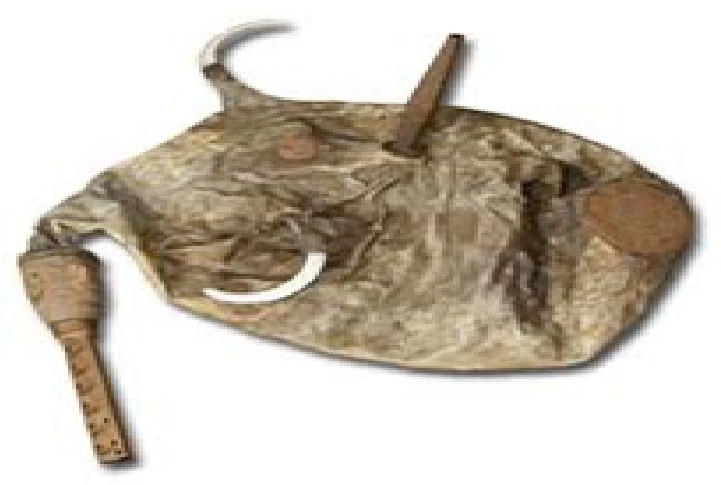

Figure 3.

Zurle (Zurna, Surrnay, Surle, or in some places Borje) - is an outdoor wind instrument, of PersianTurkish origin. Mostly, it's present in the area of Kosovo and Metohia and Macedonia. It consists of a conic wooden pipe with holes for playing, and beak-like reed, which is inserted on top. They are used in pairs: two large and two small zurna. When played, they're always held in the straight position, where one player plays the melody, while other just follows with a single tone, accompanied by a large drum - Tapan (Goč). It is made from pear, walnut or some other kind of precious wood. They are made by craftsmen in Turkey and in this region it arrived from Tunisia, Morocco or Turkey.

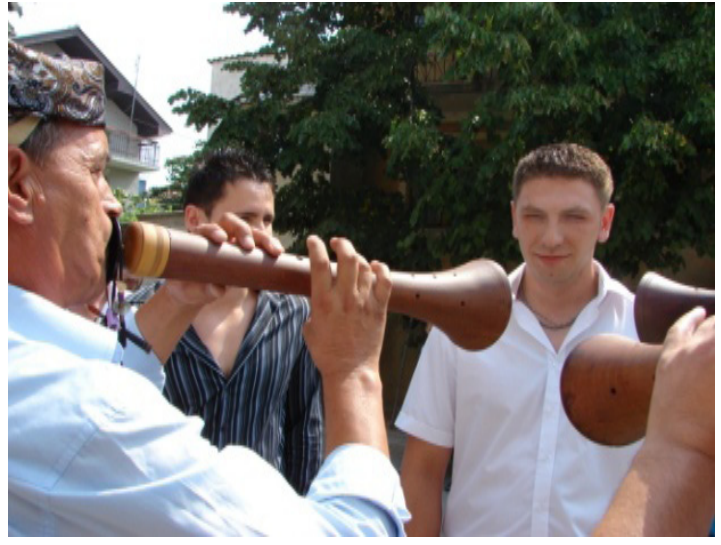

Figure 4.

GOČ-(drum, tupan)-Membranophonic instrument, which consists of a hollow cylinder, usually made of walnut, oak or beech wood with stretched animal skin (calf, sheep, donkey) on both sides. The drum is played with two sticks, bigger one mačuk (mallet like) and with sticks of field maple wood, named digere or drndalo (rumbler). It is mostly paired up with zurle and it can be used as a solo instrument for folk dances, or with kavale and pipes.

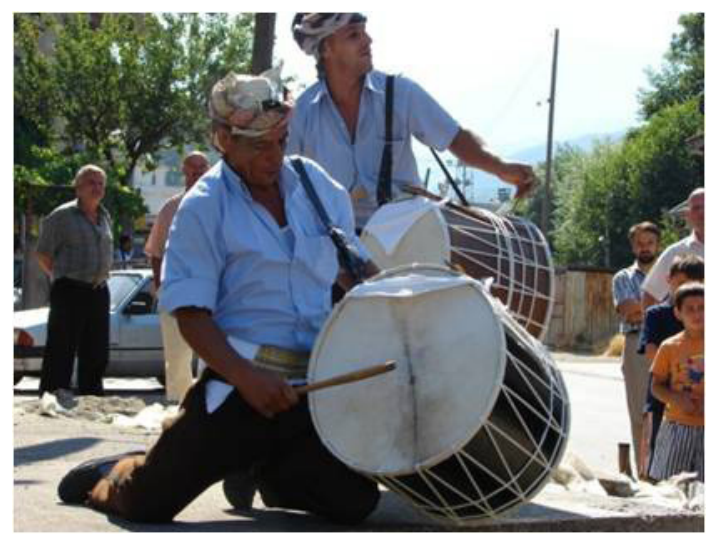

Figure 5.

KABRAN - is a small, home produced, drum that can have one or two membranes (drum heads). One-membranic, in addition to the basic purposes, could be used for clearing grain from weed seeds, as a replacement for the sieve. It main purpose was replacement for Goč or tambourine, it's used for chasing out the game during hunt, as well as for scaring off bears or badgers at night, to keep them of the corn or wheat fields. 
Sticks for beating rhythm - They were used mostly by shepherds to beat the rhythm while others played on the flute or on the kaval. These were ordinary shepherds sticks or a combination of an ordinary and a short stick. When ordinary, large shepherds sticks were used, shepherds were holding them in the middle and hit the top on the bottom one, and when they use ordinary and small stick, then the smaller one was always over the bigger one, and it was used to beat the rhythm on bigger stick .

KAVAL - aerophone instrument, widely spread in the past among shepherds. Shaped like long cylindrical tube, made of ash, linden or lilac tree, with 11 holes for playing different tones. Usually plays in a duo, and they produce very soft sound. Vlachs - cattle breeders in Macedonia consider it an instrument of God, while all others (zurle, bagpipes, drums) are diabolical. It has always been a favorite instrument in our region. There are two types of it: thick and thin kaval. Slim was used for soloing and together with thick one it makes a couple or čift. Brass kavals were specially appreciated, and had highest price, because they gave a soft, velvety sound, but also wooden kavals made of precious types of wood.

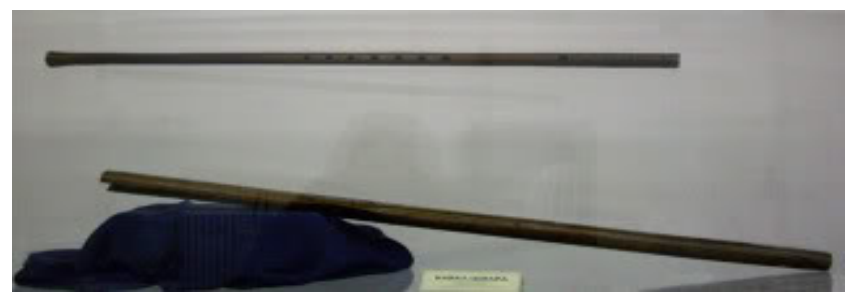

Figure 6.

\section{DAIRE (TAMBOURINE, DEF)}

Membranophonic instrument of Arab origin, which consists of a rim made of chestnut or maple wood, in which only one side has stretched sheepskin or goatskin glued with homemade yeast or glue.
The ring has six to eight slots in which are inserted and fixed flat metal rings, who, when shaken or struck, jingle. Usually, it's held in left hand while with fingers of the right hand and lower part of the hand player strike the skin. Tambourine is a rhythmic instrument whose rhythm is used for traditional or folk dances in various occasions and celebrations. It is considered feminine instrument, circular shaped percussion instrument. As a solo instrument it's commonly used by women, mostly in Kosovo and Metohia, Macedonia and Bosnia and Herzegovina.

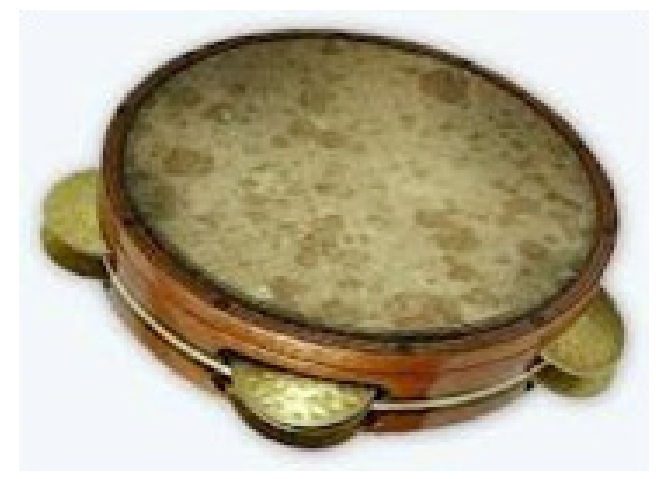

Figure 7.

DARABUKA - Membranophonic instrument of Oriental origin, made of baked clay, with affixed, or with thin thread tethered skin. When played, the instrument is held on his lap (if the player is sitting) or under his arm (if standing), and the skin is struck with the fingers of one hand. Darabuka is used as a rhythmic accompanying instrument and usually is part of the national orchestra. Territorially, this instrument prevails in Macedonia and Kosovo.

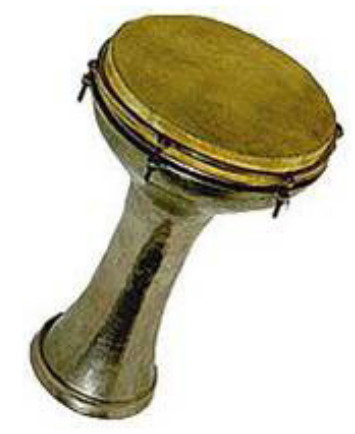

Figure 8. 
TAMBURA - was rarely used in our region. They are mainly brought from other countries by season workers. Tambura is the national string instrument. The name tambura comes from the Persian word tamburu, meaning string. The oldest preserved written document about the tambura comes from the year 1515. in Bosnia and Serbia, from travel writing of N. NICOLAEU companion of French Consul in Turkey. Later tambura expanded to Slavonia, Kosovo and Metohia, Vojvodina and ona part of southern Hungary.

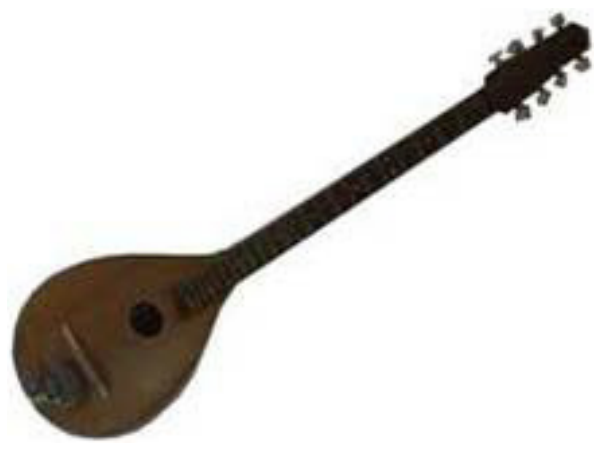

Figure 9.

ČIFTELIJA - folk string instrument. Mostly used by Albanians, it became their traditional instrument with which all almost of their folk lyric and epic poems are accompanied. There is only one pair of strings (two), hence the name comes from the Turkish word ćift - couple and teli - wire. It neck is thin and elongated and produces a thin and penetrating sound.

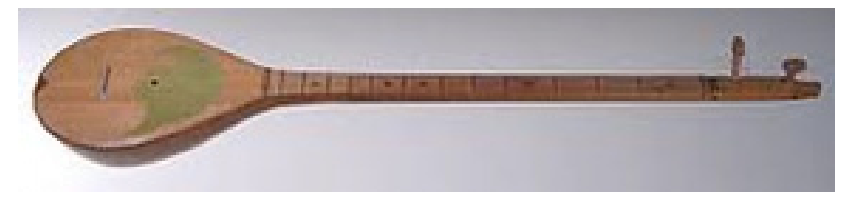

Figure 10.

\section{CONCLUSION}

Musical instruments that were mainly used in these areas are instruments that can be made manually and for one's personal needs. Instruments that were factory or mass produced for commercial purposes were very rarely are used. Especially expensive instruments that require considerable sum of money set aside by the villagers were hardly been present in this area or used adequately just for pure enjoyment. These are mainly hand-made instruments that were passed from generation to generation or inherited, so they seldom change ownership outside the original family and often ended up as souvenirs, without specific applications of it's purpose.

\section{REFERENCES}

- Džuzeley, B. (2006). Albanci v iztočni Balkan, Sofija.

- Hasani, H. (1987). Goranske narodne pesme, Priština.

- Ristoski, B. (1969). Kon proučavanjeto na narodnata poezija na Goranite, „Makedonski folklor“, Skopje. 